\title{
Rheumatic fever prevention program: long-term evolution and outcomes
}

\section{Cleonice Carvalho Coelho Mota ${ }^{1}$, Zilda Maria Alves Meira ${ }^{1}$, Rosangela Nicoli Graciano ${ }^{1}$, Fernando Felipe Graciano ${ }^{1}$ and Fátima Derlene Rocha Araújo ${ }^{2}$}

' Department of Pediatrics, Hospital das Clínicas da UFMG, Federal University of Minas Gerais (UFMG), Belo Horizonte, Brazil

${ }^{2}$ Hospital das Clínicas da UFMG, Belo Horizonte, Brazil

\section{Edited by:}

Luiza Guilherme, University of Sao

Paulo, Brazil

Reviewed by:

Alejandro Jose Lopez Magallon, Children's Hospital of Pittsburgh of UPMC, USA

Ertan Yetkin, Private Mersin Middle

East Hospital, Turkey

\section{*Correspondence:}

Cleonice Carvalho Coelho Mota, Departamento de Pediatria, Divisão de Cardiologia Pediátrica e Fetal, Universidade Federal de Minas Gerais, Avenida Prof. Alfredo Balena 190, Belo Horizonte, Minas Gerais 30130-100, Brazil

e-mail: cleomota@mdicina.ufmg.br
This investigation aims to analyze the profile of long-term evolution of rheumatic fever in children and adolescents and outcomes after the control of recurrences. The cohort involved 702 patients followed from 1.3 to 16.9 years covering the two periods, before and after the implementation of a prevention program. Besides the establishment of the Reference Center in the State of Minas Gerais and the implementation of strategies to promote the compliance to prophylaxis, a project for education of health professionals was carried out in 23 cities. In addition to the clinical and epidemiological profile, the severity of the disease was analyzed. Mixed lesions were found in $27.1 \%$, valvar regurgitation in $72.9 \%$, and complete regression of the valvar lesions was seen in $34.4 \%$ of the patients, mostly presenting mild dysfunctions. The recurrence rate per patient-year was 0.058 and out of a total of 85 recurrences, $21.4 \%$ occurred in the first and $7.5 \%$ in the second period. More severe degrees of carditis and significant valvar sequels presented a higher prevalence in patients with recurrences. The comparative analysis between the two periods showed no changes regarding the age at the primary attack, gender, type, and site of valvar lesions and affected joints; however, important modifications in the indices of severity were observed after the control of recurrences. A significant decrease in the prevalence of severe carditis, obstructive valvar sequels, hospital admissions, surgical approach, and deaths was seen. This investigation showed that although the clinical profile of presentation remains unchanged, the control of repeated attacks can improve the morbimortality rates. In this context, the secondary prophylaxis should be the first priority in the control of the disease in developing countries, taking into account the difficulties found for effective primordial and primary prevention.

Keywords: rheumatic fever, rheumatic heart disease, secondary prophylaxis, recurrences, valvar dysfunction

\section{INTRODUCTION}

Rheumatic fever (RF) and its more serious consequence, the rheumatic heart disease (RHD), continue to pose a significant problem in several parts of the world. Although the incidence of the disease in developed areas have markedly declined after the 1950s, RHD remains the leading cause of acquired cardiac disease in developing countries among patients aged from 5 to 30 years $(1,2)$. On a global scale, and considering all age groups, an estimated 15.6-19.6 million people suffer from RHD (3). As a result of a disability acquired at an early age, valvar sequels can be carried throughout life and account for increased rates of hospitalization, surgery, and death. In this setting, an estimated 6.6 million disability-adjusted life years are lost yearly to the disease worldwide (4). The socioeconomic factors involving considerable personal and collective costs constitute important determinants of the disease burden. Maternal low education level has been associated with recurrent attacks and identified as an independent risk factor for significant chronic valvar disease (5). Environmental factors, mainly poor housing and overcrowding, must also be included in this context $(1,4)$.
More recently, large-scale echocardiographic screenings have shown a prevalence of RHD much higher than previously thought, ranging from 5 to 10 -fold when compared to auscultation (6-13). It is a fact that some patients develop RHD, but the clinical history of previous acute episodes can go unnoticed due to poor access to health services or the presence of mild or subclinical valvar lesions. This scenario of underdiagnosis is worrying as without prevention of recurrences, the risks of more advanced disease are considerable. On the other hand, the overdiagnosis results in the undesirable exposure of non-rheumatic patients to the rigors of prophylaxis. Thus, an accurate diagnosis is essential to make adequate decisions in both directions. The international echocardiographic criteria for the diagnosis of RHD, recently established by the World Heart Federation, have given a very important contribution to diagnostic accuracy, mainly to the identification of patients without a past history of RF (14).

The magnitude of the valvular sequels has been associated with the degree of cardiac involvement during the acute phase (1517). Additionally, as it has long been noticed, the valve deformity can be progressive even in the absence of recurrences as a result 
from the process of cicatrization $(18,19)$. Nonetheless, repeated acute attacks play an important role in the unfavorable evolution and severity of RHD. Considering this potential evolution, it is a fact that there is no curative therapy. After the establishment of valvular damage, any treatment, clinical or surgical, is palliative (20). Faced with our limitations in the therapeutic approach of patients with RF and RHD, continuing attention must be given to the primary and secondary prophylaxis. The prompt introduction of an effective secondary prophylaxis can avoid the worsening of preexisting valvar dysfunctions or the appearance of new lesions related to the subsequent acute episodes. In areas where the disease is prevalent, control programs require investments. Strategies are needed to implement the adherence of patients to the regimes of secondary prophylaxis to avoid recurrences.

This investigation aims to analyze the profile of long-term evolution of patients with rheumatic valvar lesions and the outcomes after the control of recurrences, which followed the implementation of the Prevention Program for Rheumatic Fever-UFMG.

\section{MATERIALS AND METHODS}

\section{STUDY POPULATION AND DATA COLLECTION}

This investigation enrolled 702 children and adolescents with diagnosis of RF based on the revised Jones criteria (21). The patients were consecutively attended from July 1977 to February 2000 at the Division of Pediatric Cardiology/Hospital das Clínicas-UFMG and were followed by the same team of pediatric cardiologists over a period ranging from 1.3 to 16.9 years (mean $=6.8 \pm 2.6$ years). The age at admission ranged from 2.6 to 19.9 years (mean: $10.3 \pm 3.1$ years; median 9.8 years).

Outpatients and inpatients databases, records, and referring reports from the local health centers were retrospectively investigated for all patients with the diagnosis of RF, acute or chronic phase. Information was sought in the past history, first clinical evaluation, and follow-up, besides electrocardiogram, chest roentgenogram, and echocardiogram records.

\section{PROGRAM DESIGN AND STRATEGIES}

The patients were referred during the acute or chronic phases of the disease to the Division of Pediatric Cardiology-UFMG which, in 1986, established the Prevention Program for Rheumatic FeverUFMG. Since 1988, the university hospital has been the Reference Center in Minas Gerais, a Brazilian state with 0.59 million $\mathrm{km}^{2}, 853$ municipalities, and 19.6 million inhabitants. As part of the program, health professional education was carried out in the capital and other 22 cities of the state, grouped by regions and supported by local coordinators. The initiative also included distribution of educational material, promotion of scientific events, and was preceded by divulgation in the printed and electronic media.

The activities of the program were integrated into the existing public health infrastructure, and the following strategies have been adopted to assist patients at the Reference Center for Rheumatic Fever since 1988: the establishment of the Rheumatic Fever Outpatients Clinic at the university hospital; introduction of protocols for standardized approach to diagnosis and management; medical care and orientation provided by a multidisciplinary team; special attention to promote health education for patients and families; appointments for first visits demanded by the public healthcare state system were centralized and organized by the Health Secretary; transportation for patients and parents provided; routine clinical follow-up no longer than at every 6 months; besides the laboratorial exams demanded by clinical evaluation, routine investigation of ASO titer at 6 months' interval for all patients; echocardiographic screening for all definitive or suspected cases of RF or RHD, even those without clinical evidence of cardiac damage; reporting back to referring health centers to support the local follow-up of patients; distribution of free medication; secondary prophylaxis regimens with intramuscular benzathine penicillin injections at 21 days' interval; introduction of a prophylaxis card to control the compliance; active search for missing patients and accommodation at the university hospital for inpatients' parents.

\section{DATA ANALYSIS}

Demographical, clinical, and epidemiological data were assembled and patients were divided into two groups according to the period of admission: before and after the establishment of the program, from July 1977 to July 1988 and from August 1988 to February 2000 , respectively. The degree of carditis and valvular sequels was classified as mild, moderate, and severe according to the established criteria on the protocol for medical assistance (18). Moderate to severe and severe degrees of cardiac involvement for both acute and chronic phases were classified as significant. The characterization of an established RHD was defined at least 1 year after the acute phase. The last clinical and laboratorial evaluations in each respective period of investigation were considered for the characterization of the disease. Variables were summarized as percentage, and categorical variables were compared using Fisher exact test or Pearson's chi-square test. When $p$-value $<0.05$ was reported, results were identified as significant.

\section{INSTITUTIONAL BOARD APPROVAL}

This project was approved by the Ethics Committee on Human Research-Federal University of Minas Gerais, Belo Horizonte, Brazil. Written informed consent was obtained from the parents of patients enrolled in the study.

\section{RESULTS}

The mean age at the first acute episode was $9.1 \pm 4.1$ years. The distribution patients by gender was similar (F: 50.4\% M: 49.6\%), except for those with Sydenham chorea $(\mathrm{F} / \mathrm{M}=1.6 ; p$ : 0.0013$)$. In the distribution of patients according to the Jones criteria, carditis $(66.2 \%)$ and polyarthritis $(70.4 \%)$, isolated or combined, were the major manifestations most commonly observed.

As regards the type and site of valvular lesions in the chronic phase, valvular regurgitation was present in $72.9 \%$ and mixed lesions in $27.1 \%$ of patients. The mitral valve was the most affected. Isolated mitral dysfunction or in association with other valvar lesions were seen in $98.2 \%$ of patients and almost a half of patients (44.2\%) presented isolated mitral regurgitation. Aortic regurgitation was found in $37.8 \%$ and most often seen concurrently with an affected mitral valve. No patients with aortic stenosis or isolated mitral stenosis were seen. Complete regression of the valvular lesions at echocardiographic interrogation was observed in $34.4 \%$ of the patients, mostly presenting a mild dysfunction. Carditis was diagnosed in 465 patients and classified as severe in $39.8 \%$, moderate in $28.6 \%$, and mild in $31.6 \%$. 
According to the past history and before being admitted to the hospital, $34.6 \%$ of children and adolescents had presented recurrences, $22.2 \%$ had one, and $12.4 \%$ had two or more subsequent episodes. After admission, the recurrence rate per patient-year was 0.058 , which means that out of a total of 85 recurrent episodes, $51 / 238(21.4 \%)$ occurred during the first period of investigation and $34 / 454(7.5 \%)$ during the second one.

When the entire patient population was considered, a higher prevalence of significant carditis ( $p$ : 0.000) and more severe valvar sequels ( $p$ : 0.000) were seen in patients with recurrences (Tables 1 and 2 ).

The comparative analysis of the two periods of investigation showed that the clinical profile of the acute phase, first episodes or subsequent attacks, was unchanged regarding the age at the primary attack, gender, frequency, and site of affected joints, besides the most frequent association of valvular lesions (Table 3). However, after the decrease in the frequency of recurrences, which followed the improvement of the delivery and adherence to secondary prophylaxis, important modifications in the severity of the disease were observed during the follow-up. A decrease in the frequency of severe carditis, stenotic valvular lesions, hospital admissions, surgical approach, and deaths was noticed showing significant differences in all indices between the two periods of investigation (Table 4).

\section{DISCUSSION}

The present study confirms previous results of frequent involvement of the heart in children and adolescents with RF and the influence of recurrences in the severity of valvular sequels (5). The more patients are faced with recurrent episodes, the more advanced disease and its complications can be anticipated in the chronic phase (4). This poor outcome was seen prior to the implementation of prophylactic measures and was represented by a higher demand for hospitalization and surgery besides a higher number of deaths. Similarly, a prevalence of mitral stenosis three times higher than that presented after the control of recurrences was found, showing a shorter and unexpected time course for this age group. This accelerated progression into severe forms contrasts with the most often latent period of 20-40 years between the presentation of the obstructive lesion and the episode of RF. This trend has already been reported and may reflect the final result of multiple insults $(17,22)$. At the other end of the spectrum, we highlight the potential regression of less significant valvular regurgitation. The involution of valvular disease at echocardiographic interrogation observed in $34.3 \%$ of children and adolescents in the present investigation reinforces the need for a timely identification of patients at an early stage of the illness. Patients with mild valvular dysfunction and submitted to regular secondary prophylaxis have shown a good prognosis without detectable disease after 10 years $(23,24)$. A better cardiac condition at the time of the initial attack has also been pointed out as a factor related to improvement of mitral regurgitation (25). In this setting, the routine echocardiographic screening for all patients included in the program, even for suspect cases without clinical evidence of valvar dysfunction, contributed to an early identification of mild dysfunctions, clinical or subclinical.

\begin{tabular}{|c|c|c|c|c|c|c|}
\hline \multirow{2}{*}{$\begin{array}{l}\text { Significant } \\
\text { degree } \\
\text { of carditis }\end{array}$} & \multicolumn{2}{|c|}{ Acute episodes } & \multirow{2}{*}{$\begin{array}{l}\text { Total of } \\
\text { episodes, } \\
n(\%)\end{array}$} & \multirow[t]{2}{*}{$p$} & \multirow[t]{2}{*}{ OR } & \multirow{2}{*}{$\begin{array}{l}95 \% \\
\mathrm{Cl}\end{array}$} \\
\hline & $\begin{array}{l}\text { Primary } \\
n(\%)\end{array}$ & $\begin{array}{l}\text { Recurrences } \\
n(\%)\end{array}$ & & & & \\
\hline Yes & $141(30.3)$ & 69 (57.1) & 210 (35.9) & 0.000 & 3.093 & $\begin{array}{l}1.727- \\
5.540\end{array}$ \\
\hline No & 324 (69.7) & 51 (42.9) & $375(64.1)$ & & & \\
\hline Total $n(\%)$ & 465 (100) & $120(100)$ & $585(100)$ & & & \\
\hline
\end{tabular}

Table 2 | Prevalence of significant valvular sequels according to the presence of recurrences.

\begin{tabular}{|c|c|c|c|c|c|c|}
\hline \multirow{2}{*}{$\begin{array}{l}\text { Significant } \\
\text { valvular } \\
\text { sequels }\end{array}$} & \multicolumn{2}{|c|}{ Recurrences } & \multirow{2}{*}{$\begin{array}{l}\text { Total } \\
\text { patients, } \\
n(\%)\end{array}$} & \multirow[t]{2}{*}{$p$} & \multirow[t]{2}{*}{ OR } & \multirow{2}{*}{$\begin{array}{l}95 \% \\
\mathrm{Cl}\end{array}$} \\
\hline & $\begin{array}{l}\text { Yes, } \\
n(\%)\end{array}$ & $\begin{array}{l}\text { No, } \\
n(\%)\end{array}$ & & & & \\
\hline Yes & $98(40.4)$ & $47(10.2)$ & $145(20.2)$ & 0.000 & 3.000 & $\begin{array}{l}1.697- \\
5.302\end{array}$ \\
\hline No & 144 (59.7) & 413 (89.8) & 557 (79.4) & & & \\
\hline Total $n(\%)$ & $242(100)$ & $460(100)$ & $702(100)$ & & & \\
\hline
\end{tabular}

As expected, significant degrees of carditis were more frequently seen in patients during subsequent attacks when compared with those at primary episodes. In the comparative analysis, the control of recurrences was followed by a decrease in the frequency of severe carditis from 49.8 to $30.1 \%$ and an increase of mild carditis from 19.6 to $43.2 \%$. Additionally, the prevalence of severe cardiac involvement observed after the decrease of recurrences $(30.1 \%)$ was similar to the percentual found in all patients at a primary attack $(30.3 \%)$. These findings can be related to a timely diagnosis and the more effective measures to prevent the progression of the cardiac damage mainly in patients at the initial episode, where less significant degrees of carditis are expected.

In countries such Brazil, programs to implement the delivery of secondary prophylaxis have been recommended as a priority for RHD control $(26,27)$. This approach has shown to be cost-effective at population and community levels (26-28). When compared to primary prevention, this RHD control strategy is targeted at a small and specific populational group, and can be integrated into the existing healthcare system. It has been estimated that programs to improve secondary prophylaxis cost less than half the amount spent on tertiary prevention and less than one-seventh of that spent on primary prevention (29). The control program at UFMG has required a multi-faceted approach including continuous surveillance, and according to our observations, no single measure could be exclusively related to the outcomes. Previous divulgation by the media and the incorporation of activities into the existing health system infrastructure supported the training of 
Table 3 | Comparative analysis of the clinical profile of presentation.

\begin{tabular}{|c|c|c|c|c|c|}
\hline \multirow[t]{2}{*}{ Clinical profile } & \multicolumn{2}{|c|}{ Time interval } & \multirow[t]{2}{*}{$\boldsymbol{p}$} & \multirow[t]{2}{*}{ OR } & \multirow[t]{2}{*}{ Cl } \\
\hline & $07 / 77-07 / 88(n=248)$ & $08 / 88-02 / 00(n=454)$ & & & \\
\hline Age at primary episode (years) (mean \pm DP/median) & $8.8 \pm 5.5 / 8.8$ & $9.4 \pm 3.1 / 9.0$ & 0.0823 & & \\
\hline Gender (F/M) & 1.2 & 1.01 & 0.9090 & 1.041 & $0.598-1.812$ \\
\hline Large/small joints (\%) & $86.7 / 13.3$ & $84.5 / 15.3$ & 0.3548 & 1.084 & $0.744-1.580$ \\
\hline$\Sigma M R, M R+A R, A R+M R+M S, M R+M S$ /other associations (\%) & $94.2 / 5.8$ & $95.6 / 4.4$ & 0.3637 & 1.532 & $0.419-5.603$ \\
\hline
\end{tabular}

MS, mitral stenosis; MR, mitral regurgitation; $A R$, aortic regurgitation.

Table 4 | Comparative analysis of frequency of recurrences and indices of severity.

\begin{tabular}{|c|c|c|c|c|c|}
\hline \multirow[t]{2}{*}{ Indices of severity } & \multicolumn{2}{|c|}{ Time interval } & \multirow[t]{2}{*}{$\boldsymbol{p}$} & \multirow[t]{2}{*}{ OR } & \multirow[t]{2}{*}{ Cl } \\
\hline & $07 / 77-07 / 88(n=248)$ & $08 / 88-02 / 00(n=454)$ & & & \\
\hline Recurrences & 22.4 & 7.4 & 0.0000 & 2.163 & $1.222-4.169$ \\
\hline Severe/mild carditis & 49.8/19.6 & $30.1 / 43.2$ & 0.0000 & 1.556 & $1.129-2.144$ \\
\hline Frequency of $M S^{*} / M R$ and/or $A R$ & $33.2 / 66.8$ & $11.9 / 88.1$ & 0.0000 & 2.129 & $1.287-3.523$ \\
\hline Hospitalization & 45.4 & 28.4 & 0.0000 & 1.478 & $1.065-2.052$ \\
\hline Surgeries & 13.3 & 1.5 & 0.0000 & 3.973 & $1.860-14.539$ \\
\hline Deaths & 5.4 & 0.4 & 0.0000 & 3.591 & $1.582-22.156$ \\
\hline
\end{tabular}

MS, mitral stenosis; MR, mitral regurgitation; AR, aortic regurgitation, *associated with MR and/or AR.

healthcare providers, which was followed by the establishment of the Reference Center and the implementation of activities. Appropriate delivery of reliable forms of benzathine penicillin and the development of strategies to promote the adherence to prophylactic regimens were crucial to reach our goals. In this setting, we highlight the introduction of the prophylaxis card to control the compliance of patients and the combined actions of the multidisciplinary health team in providing information and improving the clinical assistance and relationship with patients and their families.

Considering the necessity of a continuous surveillance, the better adherence to a regular follow-up allowed the monitoring of the clinical evolution at least twice a year. It also contributed to reinforce the commitment to the use of medication besides improving communication with the referring healthcare centers. Special attention was given to adolescents. This age group was less likely to show adequate compliance to penicillin injections. As regards the ongoing debate about the interval between the doses of intramuscular benzathine penicillin for the implementation of the secondary prophylaxis, whether it should happen every 3 or 4 weeks $(24,30)$, our view is that the approach must be tailored to the epidemiological context. Our choice of the three weekly regimens took into account the frequency of the disease and the individual risks of exposure to group A streptococcus.

Although important modifications in the morbimortality indices were found in the present investigation and had already been observed in other RHD control programs, there is a clear necessity of increasing our understanding of this preventable and baffling disease, which continues to challenge clinicians and the scientific community. Moving forward, efforts must be directed toward research. In prospect, our more promising advances include the availability of a streptococcal vaccine for an effective access to primary prevention (31). As it has been pointed out by Carapetis and Zühlke in the discussion about the priorities for the global research in RF and RHD, "the major challenge, however, is not to miss the very real opportunity that now exists to translate current and future research into concrete action" (32). As a result, informed decision can be made and strategies can be defined for intervention at the individual and public health levels.

In conclusion, the results of this investigation showed that the cardiac involvement in RF remains frequent as does the association of recurrences with significant valvar dysfunction. In the scenario of the substantial burden imposed by the disease and poor longterm outcomes, the implementation of a program of secondary prophylaxis is an effective strategy to prevent recurrent RF and progression of RHD.

\section{LIMITATIONS OF THE STUDY}

This study has limitations as the data were collected retrospectively and the investigated databases and medical reports cannot be proved to be either complete or comprehensive. In addition, the quality of the Doppler echocardiographic approach and consequently the diagnosis accuracy of valvar lesions were not linear as technology has improved throughout the long period of investigation as regards the methods and quality of the equipment.

\section{ACKNOWLEDGMENTS}

We appreciate the participation of Prof. Reynaldo G. Oliveira in the medical care team at the Rheumatic Fever Outpatients Clinic. We also thank Dr. Carolina A. B. Capuruço for her support in the data analysis. 


\section{REFERENCES}

1. Steer AC, Carapetis JR, Nolan TM, Shann F. Systematic review of rheumatic heart disease prevalence in children in developing countries: the role of environment factors. J Paediatr Child Health (2002) 38:229-34. doi:10.1046/j.14401754.2002.00772.x

2. Eisenberg MJ. Rheumatic heart disease in the developing world: prevalence, prevention, and control. Eur Heart J (1993) 14:122-8. doi:10.1093/eurheartj/ 14.1.122

3. Carapetis JR, Steer AC, Mulholland EK, Weber M. The global burden of group A streptococcal diseases. Lancet Infect Dis (2005) 5:685-94. doi:10.1016/S14733099(05)70267-X

4. World Health Organization. Consultation on Rheumatic Fever and Rheumatic Heart Disease (2001: Geneva Switzerland). Rheumatic fever and rheumatic heart disease: Report of a WHO Expert Consultation, Geneva, 29 October - 1 November 2001. WHO Technical Report Series; 923. Geneva: World Health Organization (2004).

5. Meira ZMA, Goulart EMA, Colossimo EA, Mota CCC. Long term follow up of rheumatic fever and predictors of severe rheumatic valvar disease in Brazilian children and adolescents. Heart (2005) 91:1019-22. doi:10.1136/hrt.2004. 042762

6. Marijon E, Ou P, Celermajer DS, Ferreira B, Mocumbi AO, Jani D, et al. Prevalence of rheumatic heart disease detected by echocardiographic screening. $N$ Engl J Med (2007) 357:470-6. doi:10.1056/NEJMoa065085

7. Carapetis JR, Hardy M, Fakakovikaetau T, Taib R, Wilkinson L, Penny DJ, et al. Evaluation of a screening protocol using auscultation and portable echocardiography to detect asymptomatic rheumatic heart disease in Tongan schoolchildren. Nat Clin Pract Cardiovasc Med (2008) 5:411-7. doi:10.1038/ncpcardio1185

8. Paar JA, Berrios NM, Rose JD, Cáceres M, Peña R, Pérez W, et al. Prevalence of rheumatic heart disease in children and young adults in Nicaragua. Am J Cardiol (2010) 105:1809-14. doi:10.1016/j.amjcard.2010.01.364

9. Saxena A, Ramakrishna S, Roy A, Seth S, Krishnan A, Misra P, et al. Prevalence and outcome of subclinical rheumatic heart disease in India: the rheumatic (rheumatic heart echo utilization and monitoring actuarial trends in Indian children) study. Heart (2011) 97:2018-22. doi:10.1136/heartjnl-2011-300792

10. Robert K, Colquhoun S, Steer A, Reményi B, Carapetis J. Screening for rheumatic heart disease: current approaches and controversies. Nat Rev Cardiol (2013) 10:49-58. doi:10.1038/nrcardio.2012.157

11. Beaton A, Okello E, Lwabi P, Mondo C, McCarter R, Sable C. Echocardiography screening for rheumatic heart disease in Ugandan schoolchildren. Circulation (2012) 125:3127-32. doi:10.1161/CIRCULATIONAHA.112.092312

12. Miranda LP, Camargos PAM, Torres RM, Meira ZMA. Prevalence of rheumatic heart disease in a public school of Belo Horizonte. Arq Bras Cardiol (2014) 103:89-97. doi:10.5935/abc.20140116

13. Webb RH, Wilson NJ, Lennon DR, Wilson EM, Nicholson RW, Gentles TL, et al. Optimising echocardiographic screening for rheumatic heart disease in New Zealand: not all valve disease is rheumatic. Cardiol Young (2011) 21:436-43. doi:10.1017/S1047951111000266

14. Reményi B, Wilson N, Steer A, Ferreira B, Kado J, Kumar K, et al. World heart federation criteria for echocardiographic diagnosis of rheumatic heart disease - an evidence-based guideline. Nat Rev Cardiol (2012) 9:297-309. doi:10.1038/nrcardio. 2012.7

15. Olgunturk R, Canter B, Tunaoglu FS, Kula S. Review of 609 patients with rheumatic fever in terms of revised and updated Jones criteria. Int J Cardiol (2006) 112:91-8. doi:10.1016/j.ijcard.2005.11.007

16. Carapetis JR, Kilburn CJ, MacDonald KT, Walker AR, Currie BJ. Ten-year follow up of a cohort with rheumatic heart disease. Aust N Z J Med (1997) 27:691-7. doi:10.1111/j.1445-5994.1997.tb01000.x

17. Sanyal SK, Berry AM, Duggal S, Hooja V, Ghosh S. Sequelae of the initial attack of acute rheumatic fever in children from north India. A prospective 5-year follow-up study. Circulation (1982) 65:375-9. doi:10.1161/01.CIR.65.2.375

18. Mota CCC, Aiello VD, Anderson RH. Rheumatic fever. 3rd ed. In: Anderson RH, Baker T, Redington A, Rigby M, Penny D, Wernovsky G, editors. Paediatric Cardiology. Londres: Elsevier (2010). p. 1091-113.

19. Bland EF, Jones TD. Rheumatic fever and rheumatic heart disease: a twelve years report on 1000 patients followed since childhood. Circulation (1951) 4:836-43. doi:10.1161/01.CIR.4.6.836
20. Victor S. Dilemmas in the management of rheumatic heart disease. J Indian Med Assoc (1999) 97:265-70.

21. Dajani AS, Ayoub EM, Bierman FZ, Bisno AL, Denny FW, Durack DT, et al. Guidelines for the diagnosis of rheumatic fever. Jones criteria, 1992 updated. Special Writing Group of the Committee on Rheumatic Fever, Endocarditis, and Kawasaki Disease of the Council on Cardiovascular Disease in the Young of the American Heart Association. JAMA (1992) 268:2069-73.

22. Marcus RH, Sareli P, Pocock WA, Barlow JB. The spectrum of severe rheumatic mitral valve disease in a developing country: correlations among clinical presentation, surgical pathologic findings, and hemodynamic sequelae. Ann Intern Med (1994) 120:177-83. doi:10.7326/0003-4819-120-3-19940201000001

23. Majeed HA, Batnager S, Yousof AM, Khuffash F, Yusuf AR. Acute rheumatic fever and the evolution of rheumatic heart disease: a prospective 12 year follow-up report. J Clin Epidemiol (1992) 45:871-5. doi:10.1016/0895-4356(92) 90070-4

24. Lue HC, Wu MH, Wang JK, Wu FF, Wu YN. Long-term outcome of patients with rheumatic fever receiving benzathine penicillin $\mathrm{G}$ prophylaxis every three weeks versus every four weeks. J Pediatr (1994) 125:812-6. doi:10.1016/S00223476(06)80188-5

25. Kassem AS, El-Walili TM, Zaher SR, Ayman M. Reversibility of mitral regurgitation following rheumatic fever: clinical profile and echocardiographic evaluation. Indian J Pediatr (1995) 62:717-23. doi:10.1007/BF02825126

26. World Health Organization. A Review of the Technical Basis for the Control of Conditions Associated with Group A Streptococcal Infections. Geneva: Department of Child and Adolescent Health and Development (2005).

27. World Health Organization. Antibiotic use for the prevention and treatment of rheumatic fever and rheumatic heart disease in children. Second Meeting of the Subcommittee of the Expert Committee on the Selection and Use of Essential Medicines. Geneva: World Health Organization (2008). p. 1-15.

28. RHDAustralia (ARF/RHD writing group), National Heart Foundation of Australia, Cardiac Society of Australia and New Zealand. Australian Guideline for Prevention, Diagnosis and Management of Acute Rheumatic Fever and Rheumatic Heart Disease. 2nd ed. Darwin: Menzies School of Health Research (2012).

29. Michaud CM, Trejo-Gutierrez J, Cruz C, Pearson T. Rheumatic heart disease. In: Jamison DT, Mosely WH, Measham AR, Bobadilla JL, editors. Disease Control Priorities in Developing Countries. New York, NY: Oxford University Press (1993). p. 221-32.

30. Meira ZMA, Mota CCC, Tonelli E, Nunan EA, Mitre AMM, Moreira NSP. Evaluation of secondary prophylactic schemes, based on benzathine penicillin $G$, for rheumatic fever in children. J Pediatr (1993) 123:156-8. doi:10.1016/S00223476(05)81563-X

31. Mota CCC. Limitations and perspectives with the approach to rheumatic fever and rheumatic heart disease. Cardiol Young (2005) 15:580-2. doi:10.1017/ S1047951105001733

32. Carapetis JR, Zühlke LJ. Global research priorities in rheumatic fever and rheumatic heart disease. Ann Pediatr Cardiol (2011) 4:4-12. doi:10.4103/09742069.79616

Conflict of Interest Statement: The authors declare that the research was conducted in the absence of any commercial or financial relationships that could be construed as a potential conflict of interest.

Received: 09 September 2014; paper pending published: 03 October 2014; accepted: 16 December 2014; published online: 06 January 2015.

Citation: Mota CCC, Meira ZMA, Graciano RN, Graciano FF and Araújo FDR (2015) Rheumatic fever prevention program: long-term evolution and outcomes. Front. Pediatr. 2:141. doi: 10.3389/fped.2014.00141

This article was submitted to Pediatric Cardiology, a section of the journal Frontiers in Pediatrics.

Copyright (c) 2015 Mota, Meira, Graciano, Graciano and Araújo. This is an openaccess article distributed under the terms of the Creative Commons Attribution License (CC BY). The use, distribution or reproduction in other forums is permitted, provided the original author(s) or licensor are credited and that the original publication in this journal is cited, in accordance with accepted academic practice. No use, distribution or reproduction is permitted which does not comply with these terms. 